\title{
Choice of methods and indices for identifying the best parentals for synthetic varieties in faba bean
}

\author{
Fouad S. Maalouf ${ }^{a}$, María José Suso ${ }^{a^{*}}$, María Teresa Moreno ${ }^{\mathrm{b}}$ \\ ${ }^{a}$ Instituto de Agricultura Sostenible, C.S.I.C. Apdo.4084, 14080 Córdoba, Spain \\ ${ }^{b}$ Centro de Investigación y Desarrollo Agrario, Apdo 4240, 14080 Córdoba, Spain
}

(Received 19 May 1999; accepted 5 August 1999)

\begin{abstract}
The aim of this study was to determine the efficiency of different evaluation methods and indices for the prediction of the best parentals for the development of a synthetic variety of the faba bean. Our work compared topcross and poly-cross methods in two modalities ( 1 and 3 seed per hill) using four different indices, one of which was developed by us. Indices were evaluated for seed number and yield per plant. Outcrossing rates were estimated by using seven isozyme markers, the mixed mating model and the multilocus method. Indices were compared in terms of similarity in their ranking of parental genotypes, assuming that the most consistent index is that which gives the highest similarity in ranking over all the designs. There were no differences among the designs in terms of outcrossing rate. However, there were differences among parental lines and the level of outcrossing of a particular parental line depended on the spatial arrangement in the field. Ranking of parental lines based on both modalities of the poly-cross design was similar for all the indices used suggesting that the evaluation of outcrossing in poly-cross designs might be unnecessary. However, indices that take into account variability in outcrossing gave similar ranking of parental lines over both methods and modalities. Our results underline the importance of taking into account the variability in outcrossing rate when developing synthetic varieties in partially allogamous crops. (C) 1999 Inra/Éditions scientifiques et médicales Elsevier SAS.
\end{abstract}

Vicia faba / synthetic cultivar / outcrossing rate / poly-cross / top-cross

Résumé - Choix des méthodes et des index pour identifier les meilleurs parents dans les variétés synthétiques de féverole. Le but de cette étude était d'évaluer l'efficacité de différentes méthodes d'évaluation et des différents index pour prédire les meilleurs parents dans la création d'une variété synthétique. Nous avons comparé les méthodes de topcross et de poly-cross selon deux modalités et en utilisant quatre index différents dont un que nous avons développé. Les index ont été évalués pour le nombre de graines et le rendement par plante. Les taux d'allofécondation ont été estimés en utilisant sept marqueurs iso-enzymes, le modèle de croisement mixte et la méthode multiples. Les index ont été comparés en terme de similarité dans le classement des génotypes parentaux, considérant que l'index le plus cohérent

Communicated by Mervyn Humphreys (Aberystwyth, UK)

* Correspondence and reprints

ge1susom@uco.es 
est celui qui fournit la plus grande similarité de classement dans les différents dispositifs. Nous n'avons pas constaté de différences entre les dispositifs pour le taux d'allofécondation. Cependant des différences ont été constatées pour les lignées parentales et le niveau d'allofécondation de ces lignées dépend de leur arrangement spatial dans le champ. Le classement des lignées parentales selon les deux modalités du dispositif poly-cross a été le même pour tous les index, ce qui suggère que l'évaluation de l'allofécondation dans les dispositifs poly-cross n'est peut-être pas nécessaire. Néanmoins, les index qui prennent en compte la variation du taux d'allofécondation donnent des classements similaires des lignées parentales quelle que soit la méthode ou la modalité. Ces résultats soulignent l'importance de la prise en compte de la variabilité du taux d'allofécondation pour développer des variétés synthétiques dans les espèces partiellement autogames. (C) 1999 Inra/Éditions scientifiques et médicales Elsevier SAS.

Vicia faba / variétés synthétiques / taux d'allofécondation / poly-cross / top-cross

\section{Introduction}

Faba bean cultivars have a mixed mating system with a level of allogamy intermediate to high (around 0.60) [18] in southern Spain. Cross-pollination occurs as a result of pollination by apoid species, mostly solitary bees [12].

The level of cross-pollination and heterosis in yield characteristics has been considered enough to justify the production of synthetic varieties [10]. The development of a synthetic may be divided into successive breeding phases: 1) Selection of superior parent lines on the basis of their combining ability and 2) synthesis and evaluation. Breeders have used poly-cross and top-cross tests in their search for lines with superior general combining ability (GCA). These methods are based on the assumption that cross-pollination rate is equal and random for each line; thus, differences in the performance of the progenies are considered to result from variation in the ability of maternal parents to transmit high performance to their progeny. However, in partially allogamous crops, such as Vicia faba, this basic assumption may be partially invalidated and two additional factors should be taken into account: 1) different levels of autofertility and 2) different levels of outcrossing: If this is not done, GCA estimates will include a component derived from selfs as well as random mating.

The ability to identify the best parents would be enhanced by using reliable indices. Several indices $[3,4,19,20]$ have been developed to estimate synthetic value. These indices are functions of parental performance and their crosses, assuming that the crosses occur at random. However, breeding studies have shown that random cross-pollination may not occur among different lines $[1,11]$. In addition, in faba bean, variation in cross-pollination and autofertility among parentals could limit the efficiency of both the top-cross and poly-cross progeny test to detect lines with superior GCA [2]. Link and Ederer [9] developed definitions for determining varietal ability in the case of partial allogamy with genotype dependent cross-pollination.

In order to breed synthetic varieties in Vicia faba the objective of this study was to examine different breeding methods and indices to evaluate parents of synthetics. Our work compares two modalities ( 1 and 3 seed per hill) in top-cross and poly-cross progeny tests and two categories of indices: 1) Indices including the parental performance and their crosses and based on the assumption that crosses occur at random and 2) Indices that, also, take into account differences in outcrossing rate among parental genotypes.

\section{Material and methods}

\subsection{Plant material and field trials}

Thirteen genotypes were included in four different designs comprising top-cross and poly-cross methods and two modalities of planting pattern ie, poly-cross 1 ( 1 seed per hill) and poly-cross 2 ( 3 seed per hill) and top-cross 1 and 2 ( 1 and 3 seeds per hill respectively). In all the planting designs genotypes were sown at a distance of $50 \mathrm{~cm}$ between the rows and $10 \mathrm{~cm}$ between the 
hills within a row. A mixture of open pollinated hybrids and open pollinated cultivars was used as a tester in the top-cross designs. Top-cross modality 1 was evaluated during two years.

\subsection{Analytical procedures}

Six plants per genotype and twelve seeds per plant were assayed. Seed were assayed for five enzyme systems. Electrophoretic procedures, inheritance and linkage analysis of the enzyme were described by Suso et al. [17]. In total, seven polymorphic loci were studied, (6 Pgd, Skd, Est, Sod-1, Sod-2, Sod-3 and Idh).

\subsection{Model for outcrossing rates}

Mean for single-locus (ts) and multilocus (tm) estimates of outcrossing rates were calculated for every design by using the maximum likelihood procedure given by Ritland and El-Kassaby [15] and Ritland's MLT program [14]. The multilocus procedure, using all the genotypic categories and information from several loci is more efficient at detecting outcrossing events than single locus models and also gives estimates of family outcrossing rates for pollen gene frequency set constant and equal to the population gene frequency. Although the progeny array size, 12 , is small to obtain precise family mating system estimates, most of the estimates converge and those estimates that did not converge were not used. Outcrossing among relatives is possible in a poly-cross design and it has been argued that the single locus procedure will underestimate outcrossing rate if related matings other than selfs occur in populations. However, multilocus outcrossing estimates are expected to be much less biased by outcrossing among relatives. Thus, if means for single locus estimates in a population are smaller than multilocus estimates, inbreeding other than selfing is indicated [16].

Anovas were performed to determine the effect of methods (top-cross and poly-cross), modalities ( 1 and 3 seed per hill), parental line and year on the outcrossing estimates. Line and year were considered random and methods and modalities fixed effects. An angular transformation was performed on percentages prior to analysis.

\subsection{Indices}

The synthetic cultivar performance was predicted by using the following indices: 1) Indices combining the

Table I. Indices used for predicting the best parental lines.

Name and origin

Synthetic value [19]

(Wricke and Weber, 1986)

Parental value in synthetics [3] applied

in a poly-cross design

Parental value in synthetics (Modified index of Ederer and Link [3]) applied in top-cross design

General Varietal ability of Link and Ederer [9]

Synthetic value for partially outcrossing crops

\section{Indices}

$$
\begin{aligned}
& S V_{i}=\frac{1}{k} v_{i}+\frac{k-1}{k} 2 g c a_{i} \\
& F_{i}=P_{i}+\frac{k-1}{k} \frac{N}{N-1}\left(C_{i}-P_{i}\right) \\
& F_{i}=\frac{1}{k} P_{i}+\frac{k-1}{k} C_{i} \\
& G V A(K)_{i}=V_{i}+\mu_{i} \frac{k-1}{k}\left(2 g c a_{i}-v_{i}\right)+ \\
& \delta_{i} \frac{k-1}{k}\left(\bar{C}+g c a_{i}-\bar{P}-v_{i}\right) \\
& S V_{i}=v_{i}+\mu_{i} \frac{k-1}{k}\left(2 g c a_{i}-v_{i}\right)+\delta_{i} \frac{k-1}{k}\left(C_{i}-P_{i}\right)
\end{aligned}
$$

$\mu_{1}$ : mean of outcrossing rate of all parental line; $\delta_{i}$ : deviation of outcrossing rate of parent i respect to $\mu_{i} ;$ gca $:$ general combining ability of line $\mathrm{i} ; \bar{P}$ : mean value of all parental lines in self fertilisation; $\mathrm{v}_{\mathrm{i}}$ : deviation of parent $\mathrm{i}$ respect to $\bar{P}$; $\mathrm{k}$ : number of components in the synthetics; $\mathrm{N}$ : number of all components in the polycross design; $\mathrm{C}_{\mathrm{i}}$ : value of all crosses between the parental line $\mathrm{i}$ and the all others components; $\bar{C}$ : mean value of all crosses of all parental lines; $\mathrm{P}_{\mathrm{i}}$ : Parental value of line i in self-fertilisation. 
parental performance and their crosses: (a) the synthetic value (SV) of Wricke and Weber [19], (b) the value of a parental component for a synthetic variety of Ederer and Link [3] applied to poly-cross design and (c) a modification of this index applied to a top-cross design (See appendix part B); (2) Indices that take into account the variability in outcrossing rate: (a) general varietal ability in the case of partial allogamy with a genotype dependent degree of cross-fertilisation, Link and Ederer [9] and (b) a new synthetic value derived by us taking into account the variability among parental lines in outcrossing rate (See appendix part A). Table I summarises the indices used. Estimates of the four indices were obtained for yield per plant and seed number per plant.

Indices were compared in terms of similarity of ranking between genotypes in a design and the most consistent index was identified as giving the highest similarity in ranking across the designs. Spearman's correlation coefficients were computed to determine similarity among rankings.

\section{Results}

\subsection{Estimates of outcrossing rate}

Estimates of mean single-locus, multilocus and parental outcrossing rates for the four designs are shown in table II.
The level of outcrossing was lower in poly-cross 1 (1 seed/hill) than in poly-cross 2 (3 seed/hill), top-cross 1 and top-cross 2, although the differences were not significant. The multilocus outcrossing estimate for top-cross 1 was lower in the second year $(P>0.05)$

The mean of the single locus estimates is close to the multilocus estimate for each design except for poly-cross 2 and top-cross 1 in the second year. In these cases means of the single locus estimates are smaller suggesting that inbreeding other than selfing is possible.

The analysis of variance indicated the presence of significant variation $(P<0.001)$ among individual genotypes for outcrossing rate over designs and years. No significant variation for outcrossing rate between methods (top-cross and poly-cross) and modalities ( 1 or 3 seed per hill) was observed. However, the interaction between parental lines and modalities was highly significant $(P<0.001)$. The other interaction between method and line was not significant $(P>0.05)$, but the interaction between methods and modality and the triple interaction method $\mathrm{x}$ modality $\mathrm{x}$ parental line were sig-

Table II. Multilocus, mean of single-locus and parental line outcrossing rate estimates for the four designs of poly-cross and top-cross in two years.

\begin{tabular}{lccccc}
\hline Genotypes & P1(1) & T1(1) & P2(1) & T2(1) & T1(2) \\
\hline $\mathrm{t}_{\mathrm{m}}$ & 0.4030 & 0.5220 & 0.5200 & 0.4730 & 0.4000 \\
$\mathrm{t}_{\mathrm{s}}$ & 0.3750 & 0.4666 & 0.5000 & 0.4666 & 0.3590 \\
Lp1 & 0.4583 & 0.7283 & 0.5183 & 0.6100 & 0.4120 \\
Lp3 & 0.4083 & 0.4716 & 0.2200 & 0.6266 & 0.3819 \\
Lp4 & 0.3166 & 0.6700 & 0.7150 & 0.4466 & 0.4048 \\
Lp5 & 0.3300 & 0.5816 & 0.3883 & 0.5350 & 0.6022 \\
Lp6 & 0.5700 & 0.6233 & 0.6466 & 0.3716 & 0.5133 \\
Lp7 & 0.0000 & 0.1166 & 0.3240 & 0.0000 & 0.0000 \\
Lp8 & 0.5333 & 0.5820 & 0.5283 & 0.5283 & 0.4738 \\
Lp9 & 0.3533 & 0.4966 & 0.5216 & 0.4883 & 0.3720 \\
Lp12 & 0.4250 & 0.1816 & 0.3383 & 0.3116 & 0.1613 \\
Lp13 & 0.0866 & 0.2600 & 0.7133 & 0.3966 & 0.4491 \\
Lp15 & 0.5716 & 0.5516 & 0.5616 & 0.6283 & 0.4115 \\
Lp17 & 0.6283 & 0.6850 & 0.3325 & 0.3483 & 0.6285 \\
Lp18 & 0.2966 & 0.3183 & 0.6620 & 0.4066 & 0.6567 \\
\hline
\end{tabular}

P1: Poly-cross1; P2; Poly-cross2; T1: Top-cross 1; T2: Top-cross2. (1): first year, (2) second year. 
Table III. Rank correlation's coefficients between the four designs across the four indices for yield in two years.

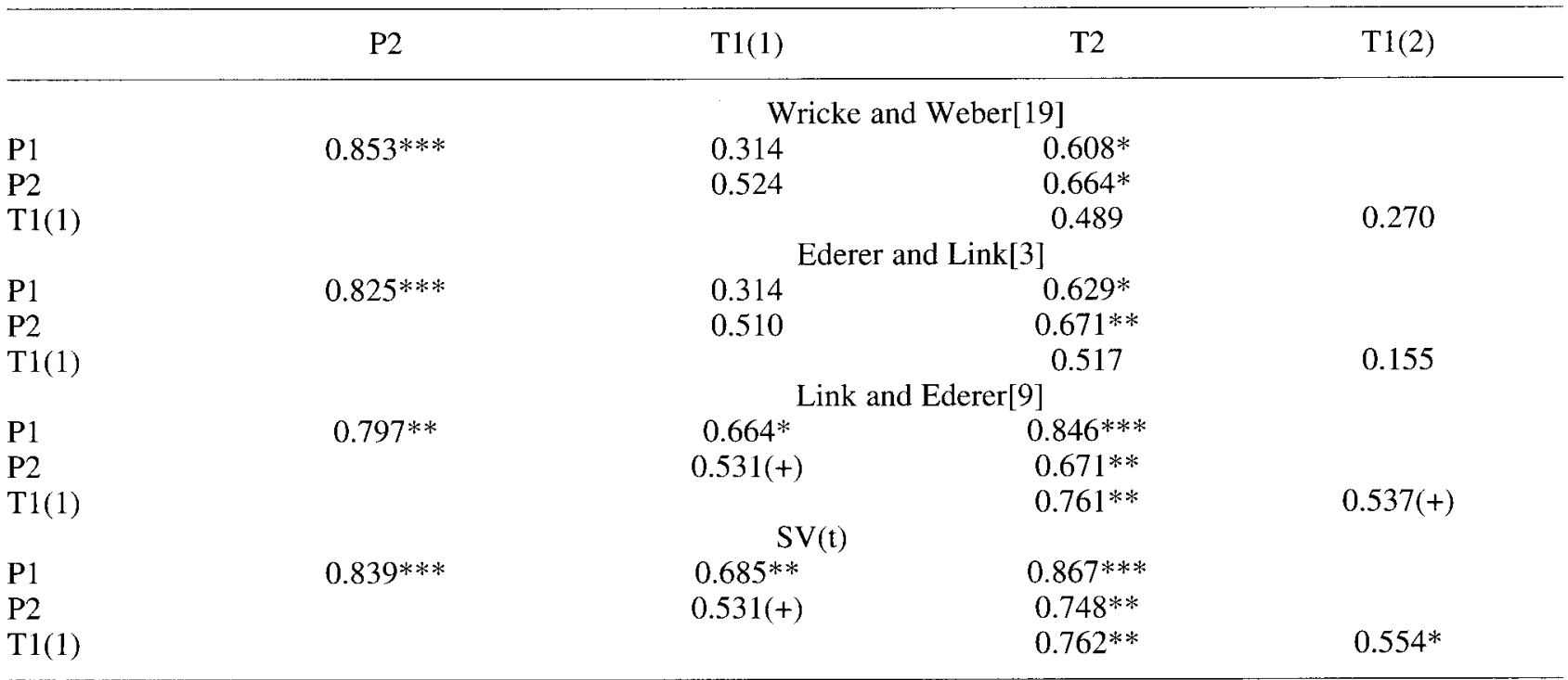

P1: Poly-cross1, P2: Poly-cross2, T1: Top-cross1, T2: Top-cross2, (+): $P<0.07$. 1: first year, 2: second year

nificant $(P<0.05)$. The year $\mathrm{x}$ line interaction for the top-cross design was not significant.

\subsection{Synthetic cultivar prediction}

Spearman's rank correlation coefficients are presented in table III for the four designs, across every index for yield per plant including $\mathrm{T} 1$ for two years. The largest correlation coefficient was found between both modalities of the poly-cross method and over all indices. However, the correlation between the rankings for both modalities of the top-cross is only high for the indices that take into account variability in outcrossing rate. There is no significant correlation between both modalities of the top-cross across the other indices. Correlation among the rankings for top-cross 1 in both years is very small and only significant for the indices that take account of the variability in outcrossing rate among the parental lines The ranking correlation between poly-cross and both top-cross methods depends on the modality of the top-cross and the indices used. Only the indices that take into account the variability of outcrossing rate show significant correlation between the poly-cross and both top-cross methods.

In summary, the largest and most consistent correlations were observed for the indices that incorporate outcrossing variability. The design that showed the highest correlation across all the methods and indices was the top-cross modality three seed per hill. Rank correlation coefficients for seed number per plant were lower than for yield, but showed the same trend as that described for yield per plant (data not presented).

\section{Discussion}

Synthetic cultivars are produced by intercrossing a number of parental lines selected on the basis of their combining ability in all possible combinations with the resulting population being maintained by open pollination among the lines. Therefore, the choice of parents is critical for success and evaluation methods must be effective. Breeders have used poly-cross and top-cross methods and different indices in their search for superior parents. Most of the indices used in faba bean to identify the best 
parents for a synthetic variety fall into two broad categories: 1) indices that incorporate the value of the parents and their crosses and 2) indices that also take into account variability in outcrossing rate.

No significant differences were found in the level of outcrossing between the poly-cross and top-cross methods and the 1 and 3 seed per hill modalites. Top-cross 1 and poly-cross 2 produced the same level of outcrossing however in polycross 2 the mean of the single locus estimates was lower than the multilocus estimates indicating that there were crosses between plants of the same genotype in this design. The mean of the single locus estimates was also lower in top-cross $1 \mathrm{sec}-$ ond year, which may be explained by a heavy infestation of the parasite broomrape (Orobanche crenata) that considerably reduced the number of plants in the design.

There was high variability among parental lines in the level of outcrossing. Our results also showed that, although there were no differences in outcrossing between the 1 and 3 seed per hill modalities, the interaction between modality and parental line was high. So, a particular parental line may show low and high outcrossing depending on the modality, that is the spatial arrangements of the lines. Carré et al. [1] found that spatial arrangements of genotypes can modify pollinator movements and may or may not facilitate pollen dispersal. Link [8] showed that cross-fertilisation may also be affected by the autofertility of a line. Our result can be explained if the level of outcrossing of a particular parental line depends both on spatial arrangement and autofertility. In faba bean, it appears that, due to its mating system, the development of a successful synthetic could depend on knowing more than just the performance of parents and crosses.

The ranking of parentals based on both modalities of the poly-cross was the same for all the indices used. Agreement between rankings for the two categories of indices suggests that the evaluation of outcrossing in poly-cross designs might be unnecessary. Similar results have been shown by Ederer and Link [3]. These researchers concluded that rankings based on a combination of parental performance per se and general combining ability was fairly adequate to select parentals for synthetic cultivars when using a poly-cross test. However, ranking of parental lines based on both modalities of the top-cross was found to be highly correlated only when using indices that take into account variability of outcrossing rate. It has been suggested that a very high correlation should be obtained between rankings in poly-cross and top-cross designs. However, our results showed that the topcross and poly-cross design in faba bean are only equivalent if indices are used that take into account variability in outcrossing rate. Prediction of the best parents should be improved considerably if variability in outcrossing is included in the indices used for ranking.

The correlation between both modalities of the poly-cross and top-cross modality three seeds per hill is maintained over all indices. In contrast, with indices that do not incorporate variability in outcrossing the ranking based on the top-cross 1 is different to the ranking based on the poly-cross designs. The high correlation between the polycross method and top-cross modality three seeds per hill suggest the importance of spatial arrangements and autofertility in determining the level of intercrossing among lines. It has been shown that pollen carry over by most pollinators is limited to a few meters $[6,7,13]$. Our results underline the importance of understanding how pollen moves between plants in determining the level of outcrossing.

In conclusion, ranking of parentals is equivalent over methods and modalities when indices are used that take into account variability in outcrossing. However correlations are not complete and we suggest use of top-cross method, modality 1 seed per hill in order to increase intercrossing and prevent an unconscious selection of genotypes with higher autofertility. It is advisable to avoid poly-cross methods and top-cross 2 modality because crosses among plants of the same parental line are evident. Further work is underway in order to correlate the predicted synthetic performance of each index and the realised results. 
Link and Ederer [9] proposed a method of screening for the degree of cross-pollination in practical breeding. However, indices that take account of variability in outcrossing rate have not found widespread use in plant breeding. One of the major reasons is that plant breeders feel that the resources needed to measure outcrossing rate are not worth the effort. This may be true in some cases if it is necessary to use morphological markers. However use of isozyme markers (5) to measure outcrossing rates can offer clear advantages in constructing synthetic varieties.

Acknowledgements: The authors are very grateful to Amparo Martinez and Juan Prieto for their technical assistance.

\section{References}

[1] Carré S., Taséi J. N., Badenhauser I., Le Guen J., Morin G., Pierre J., Gene dispersal by Bumblebees between two lines of faba bean, Crop Sci. 38 (1998) 322-325.

[2] Cubero J.I., Breeding methods for stress resistance in cross-pollinated crops, in: Singh K.B., Saxena M.C. (Eds.), Breeding for stress tolerance in cool season food legumes, ICARDA, Aleppo, 1993, pp. 439-457.

(3] Ederer E., Link W., The poly- cross test as a step in breeding partially allogamous crops, Theoretical considerations. Proc. XIIIth EUCARPIA Congress, Book of poster Abstracts, Angers, 1992, pp. 543-544

[4] Gallais A., Development and application of prediction formulae for synthetics, Ann. Amelior. Plantes 26 (1976) 623-628.

[5] Hackenberg E.M., Köhler W., Use of isozyme analysis in the breeding of synthetic rapeseed cultivars, Plant Breeding 11 (1996) 474-479.

[6] Handel S.N., Pollination ecology, plant population structure, and gene flow in: L. Real, (Ed.), Pollination Biology, Academic Press, New York, 1983, pp. 163-211.

[7] Kevan P.G., Pollination biology and plant breeding systems, in: Shivanna K.R., Sawhney V.K. (Eds.), Pollen biotechnology for crop production and improvement, Cambridge University Press, Cambridge, 1997, pp. $59-83$.

[8] Link W., Autofertility and rate of crossfertilization: crucial characters for breeding synthetic varieties in faba beans (Vicia faba L.), Theor. Appl. Genet. 79 (1990) 713-717.

[9] Link W., Ederer E., The concept of varietal ability for partially allogamous crops, Plant Breeding 110 (1993) 1-8.

[10] Link W., Stelling D., Ebmeyer E., Factors determining the performance of synthetics in Vicia faba L.1. Heterogeneity, heterozygosity, and degree of cross-fertilization, Euphytica 75 (1994) 77-84.

[11] Mesquida J., Le Guen J., Taséi J.N., Carre S., Morin G., Modalités de la pollinisation chez deux lignées de feverole de printemps (Vicia faba L. var. equina Stendel). Effects sur les coulures, la productivité et les taux de croisements, Apidologie 21 (1990) 511-525.

[12] Pierre J., Suso M. J., Cartujo F., Moreno M. T., Esnault R., Le Guen J., Comparaison de L'Entomofaune Pollinisatrice (Hymenoptera: Apidae) de la feverole sur 2 sites en France et en Espagne. Biodiversité et efficacite. IV eme Conference Internationale Francophone d'Entomologie, Saint Malo, 1998.

[13] Richards A.J., Plant Breeding Systems, Allen and Unwin, London, 1986, $529 \mathrm{p}$.

[14] Ritland K., A series of Fortran computer programs for estimating plant mating systems, J. Hered. 81 (1990) 235-237.

[15] Ritland K., El-Kassaby Y.A., The nature of inbreeding in a seed orchard of Douglas fir as shown by an efficient multilocus model, Theor. Appl. Genet. 71 (1985) 375-384.

[16] Shaw D.V., Allard R.W., Estimation of outcrossing rates in Douglas fir using isozyme markers, Theor. Appl. Genet. 62 (1982) 113-120.

[17] Suso M.J., Moreno M.T., Cubero J.I., New isozyme markers in Vicia faba: inheritance and linkage, Plant Breeding 111 (1993) 170-172.

[18] Suso M. J., Moreno M.T., Cubero J.I., Crosspollination in Vicia faba in Southern Spain, $2^{\text {nd }}$ European Conference on Grain legumes. Improving Production and Utilisation of Grain Legumes, Copenhagen, 1995.

[19] Wricke G., Weber W.E., Quantitative genetics and selection in plant breeding, Walter de Gruyter, Berlin New York, 1986, 406 pp.

[20] Wright A.J., Inbreeding in synthetic varieties of field beans (Vicia faba L.), J. Agric. Sci. 89 (1977) 459-501. 


\section{Appendices}

\section{Part A}

We have proceeded in the following way in order to develop the expression of Synthetic value for partially allogamous crops:

1) According to Cubero [2], the value of a parental line in synthetics for a partially allogamous species is a mixture of true hybrids and selfed progenies and can be expressed:

where:

$$
F_{i}=\left(1-t_{i}\right) P_{i}+t_{i} S_{i}
$$

$t_{i}$ : outcrossing rate value of line $i$.

$\mathrm{P}_{\mathrm{i}}$ : parental line value in self-fertilisation.

$\mathrm{S}_{\mathrm{i}}$ : parental line value in open-pollination

2) According to Gallais [4] the general combining ability of top-cross and poly-cross progenies can be expressed:

where:

$$
g c a_{i}=\frac{g_{i}+\sum_{\substack{j=1 \\ j \neq i}}^{k-1} g_{j}}{2}
$$

$g_{i}:$ the female genetic effect

$g_{j}$ : the male effect of the paternal line $\mathrm{j}$.

3) P, S and t of equation (1) are expressed as follow:

$$
\begin{array}{lc}
\mathrm{P}: & P_{i}=\bar{P}+v_{i} \\
\mathrm{~S}: & S_{i}=\frac{1}{k} P_{i}+\frac{k-1}{k} C_{i j} \\
\mathrm{t}: & t_{i}=\mu_{i}+\delta_{i}
\end{array}
$$

Where:

$\bar{P}:$ The mean of all parental lines in self fertilisation $v_{\mathrm{i}}$ : Deviation of parent i respect to $\bar{P}$.

$\mathrm{C}_{\mathrm{ij}}$; the value of all crosses between the maternal line $\mathrm{i}$ with all $(\mathrm{k}-1)$ paternal lines. This value can be expressed as:

$$
C_{i j}=\bar{C}+g_{i}+\sum_{\substack{j=1 \\ j \neq i}}^{k-1} g_{j}
$$

$\mu_{t}$ : mean value of outcrossing rate of all parental lines. $\delta_{i}$ : Deviation of outcrossing rate of parent i respect to $\mu_{t}$ $\mathrm{k}$ : number of all parental lines into the design. In the following expressions $C_{i j}$ is substituted by $C_{i}$

4) Substituting (6), (3) and (2) in (4):

$$
S=\left(\frac{1}{k} \bar{P}+\frac{k-1}{k} \bar{C}\right)+\left(\frac{1}{k} v_{i}+\frac{k-1}{k} 2 g c a_{i}\right)
$$

5) Substituting (7), (5) and (3) in (1):

$F_{i}=\left(1-\mu_{i}-\delta_{i}\right)\left(\bar{P}+v_{i}\right)+\left(\mu_{t}+\delta_{i}\right)\left[\left(\frac{1}{k} \dot{P}+\frac{k-1}{k} \bar{C}\right)+\left(\frac{1}{k} v_{i}+\frac{k-1}{k} 2 g c a_{i}\right)\right]$

Rearranging this expression we obtain:

$$
F_{i}=\bar{P}+\mu_{i} \frac{k-1}{k}(\bar{C}-\bar{P})+\left\{v_{i}+\mu_{i} \frac{k-1}{k}\left(2 g c a_{i}-v_{i}\right)+\delta_{i}^{k-1} k\left(C_{i}-P_{i}\right)\right\}
$$

Applying the definition of Synthetic value:

$$
S V_{i}=v_{i}+\mu_{i} \frac{k-1}{k}\left(2 g c a_{i}-v_{i}\right)+\delta_{i} \frac{k-1}{k}\left(C_{i}-P_{i}\right)
$$

This expression is the most general model of the Synthetic value.

It is necessary to point out that in the case of all lines have the same level of outcrossing rate, $\delta$ expression 10 is zero and is reduced to that of Wricke and Weber (19):

$$
S V_{i}=\frac{1}{k} v_{i}+\frac{k-1}{k} 2 g c a_{i}
$$

The expression (9) is reduced to that of Ederer and Link [3] for a poly-cross and assuming that there are no differences in outcrossing rate among the lines.

$$
F_{i}=P_{i}+\frac{k-1}{k} \frac{N}{N-1}\left(C_{i}-P_{i}\right)
$$

Where $\mathrm{N}$ number of lines in the designs

\section{Part B}

Formulae number (12) can also be applied when assaying the top-cross design. The tester in this case should be mixed lines with a broad genetic base. Thus $\frac{N}{N-1}$ équation is approximately equal to 1 . Consequently the expression (12) is reduced to the following one.

$$
F_{i}=\frac{1}{k} P_{i}+\frac{k-1}{k} C_{i}
$$

